\title{
Impact of Vertically-Suspended Environmental Enrichment and Two Densities of Fish on Circular Tank Velocity Profiles
}

\author{
Joshua M. A. Caasi ${ }^{1}$, Joseph M. Barnes ${ }^{1}$, Michael E. Barnes ${ }^{2}$ [C] \\ ${ }^{1}$ Benedictine College, School of Engineering, Atchison, Kansas, USA \\ ${ }^{2}$ South Dakota Department of Game, Fish and Parks, McNenny State Fish Hatchery, Spearfish, South Dakota, USA \\ Email: mike.barnes@state.sd.us
}

How to cite this paper: Caasi, J.M.A., Barnes, J.M. and Barnes, M.E. (2020) Impact of Vertically-Suspended Environmental Enrichment and Two Densities of Fish on Circular Tank Velocity Profiles. Engineering, 12, 723-738.

https://doi.org/10.4236/eng.2020.1210051

Received: September 10, 2020

Accepted: October 18, 2020

Published: October 21, 2020

Copyright $\odot 2020$ by author(s) and Scientific Research Publishing Inc. This work is licensed under the Creative Commons Attribution International License (CC BY 4.0).

http://creativecommons.org/licenses/by/4.0/

\section{(c) (i) Open Access}

\begin{abstract}
Vertically-suspended environmental enrichment has been shown to produce improvements in fish growth during hatchery rearing in circular tanks. This study documented the effects of a novel suspended structure on the velocity profile of a 3.63-m diameter circular tank containing juvenile landlocked fall Chinook salmon (Oncorhynchus tshawytscha) at two different densities (9.0 and $\left.34.3 \mathrm{~kg} / \mathrm{m}^{3}\right)$. The addition of vertically-suspended structure to the tank significantly decreased velocities at nearly every sampling point, with velocities typically dropping from $15 \mathrm{~cm} / \mathrm{s}$ without structure to less than $6 \mathrm{~cm} / \mathrm{s}$ when structure was present. Fish density also significantly impacted in-tank velocities, with an inverse relationship observed between the density of fish and water velocity. Significant interactions were present among the presence or absence of structure and fish density. When structure and fish were absent, the velocity at the edge of the tank was $15.63 \mathrm{~cm} / \mathrm{s}$, which was significantly higher than the $4.75 \mathrm{~cm} / \mathrm{s}$ velocity when both structure and the lower fish density were added, which was in turn significantly higher than the $2.29 \mathrm{~cm} / \mathrm{s}$ velocity observed with structure and higher fish density. Despite the potentially unique features of this study, vertically-suspended environmental enrichment and the presence of fish clearly alter circular tank water velocities, which may at least partially explain the improvements in fish rearing performance observed with the use of suspended structure.
\end{abstract}

\section{Keywords}

Circular Tank, Velocity, Environmental Enrichment, Fish Density

\section{Introduction}

Circular tanks are commonly used in aquaculture and are well-suited for fish 
production [1] [2] [3]. They are inherently self-cleaning with relatively uniform water quality because of the rotational flows resulting from water entering through a tangential spray bar and exiting through a central drain [1] [2] [3] [4]. The rotational flows can also be adjusted to optimize likely beneficial fish exercise [5] [6] [7] [8].

Timmons et al. [1], Tvinnereim and Skybakmoen [9], Davidson and Summerfelt [10], Oca and Masalo [3], Lekang [11], and Plew et al. [12] have all documented the water velocity profiles in circular tanks. In general, water rotating tangentially to the tank wall creates a second radial rotation which is fastest towards the edge of the tank, and if fast enough, carries the fish waste from the bottom of the tank to the drain [1]. However, circular tank water flow patterns can be influenced by tank dimensions, water inlet structure geometry, outlet structure numbers and locations, fish numbers and sizes, and incoming water velocity and flow [3] [9] [10] [12] [13]. Environmental enrichment present in the circular tank can also significantly affect velocity profiles [14] [15].

Environmental enrichment is the modification of typically barren hatchery rearing tanks to simulate natural habitats or make more complex rearing environments [16]. In practice, environmental enrichment has included placing rocks, plant and root materials, or cement bricks in tanks [17]-[24]. However, placement of objects on the tank bottoms can severely affect flow patterns and directly reduce or eliminate the effectiveness of tank self-cleaning, leading to increased tank-cleaning labor and increased fish health risks from trapped organic matter [1] [3] [9] [24] [25] [26] [27]. The use of structures suspended from the top of circular tanks has allowed for the addition of environmental enrichment without the loss of hydraulic self-cleaning [28]. Vertically-suspended environmental enrichment has been shown to improve the growth and hatchery rearing efficiencies for numerous salmonid species [28]-[35].

The effects of vertically-suspended structures on circular tank water velocity profiles have been reported by Moine et al. [14] and Muggli et al. [15]. However, both studies used 1.8-m diameter tanks and suspended arrays of small aluminum rods. Neither Moine et al. [14] nor Muggli et al. [15] examined the interaction of fish and vertically-suspended enrichment; all of their measurements were in tanks devoid of fish. Given that tank size, the presence of fish, and environmental enrichment structures can all impact within-tank water velocity profiles [9] [12] [14] [15] [36], additional information on circular tank water flow patterns in larger tanks containing fish with different environmental enrichment structures is needed. Thus, the objective of this experiment was to document water velocities in circular tanks larger in diameter than $1.8-\mathrm{m}$, with and without the presence of fish, and with and without the presence of a novel vertically-suspended environmental enrichment structure.

\section{Methods}

All data was collected in a $3.63-\mathrm{m}$ diameter, $0.71-\mathrm{m}$ water-depth stainless-steel sided, cement bottom, circular tank fitted with a square central drain and a ho- 
rizontal spray bar (Figure 1 and Figure 2) at McNenny State Fish Hatchery in rural Spearfish, South Dakota, USA. Water height was maintained in tank at a height of $0.7 \mathrm{~m}$, and the incoming water flow rate was $288 \mathrm{~L} / \mathrm{min}$. Water velocity profiles for the tank were developed under six different scenarios: 1) fish absent from the tank and no vertically-suspended environmental enrichment, 2) fish absent with enrichment, 3) fish present at a lower density and no enrichment, 4) fish present at a lower density with enrichment, 5) fish present at a higher density and no enrichment, and 6) fish present at a higher density with enrichment (Table 1). The vertically-suspended environmental enrichment consisted of a 43 $\times 117 \mathrm{~cm}$ array of 20 pieces (diameter $=4.34 \mathrm{~cm}$; length $=0.94 \mathrm{~m}$ ) of polyvinyl chloride electrical conduit protruding downward from an overhead plastic cover as described by White et al. [35]. The conduit pieces were evenly spaced, approximately $16.5 \mathrm{~cm}$ apart. The array was approximately $58 \mathrm{~cm}$ from the tank edge and was located $90^{\circ}$ from the spray bar where water entered the tank (Figure 3).

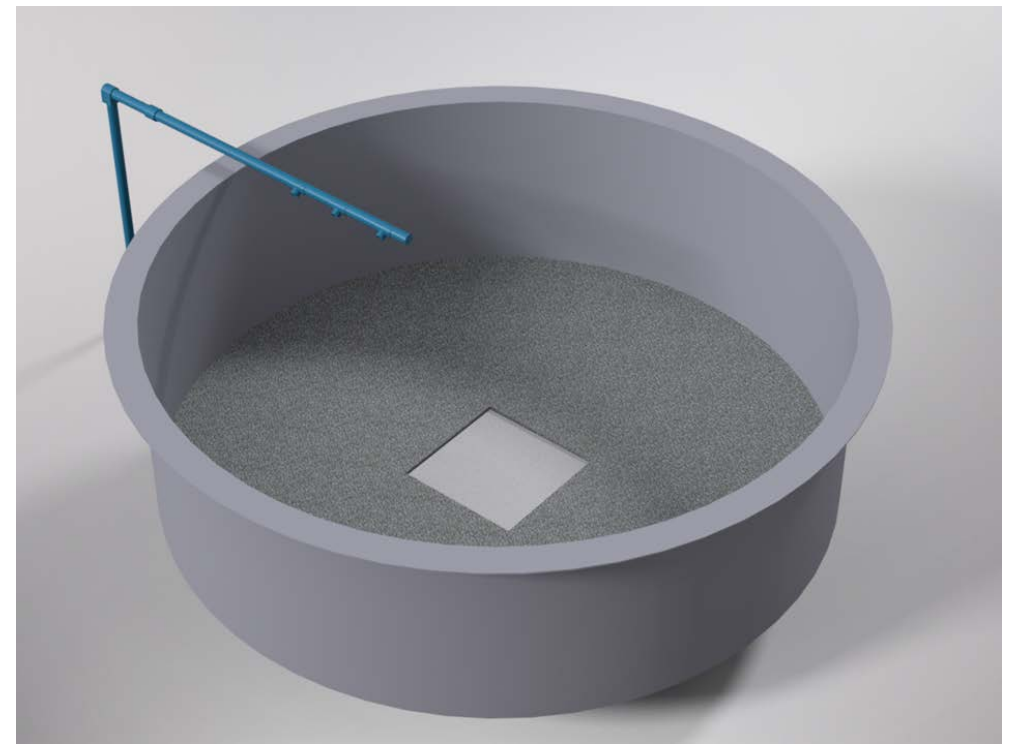

Figure 1. Diagram of a circular tank with horizontal spray bar and centralized drain.

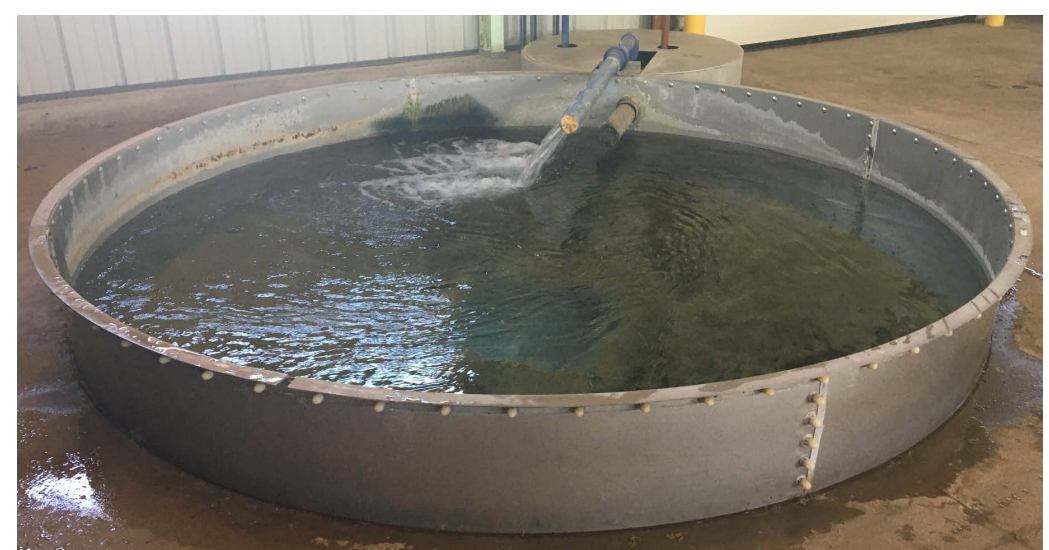

Figure 2. Picture of the tank in situ at McNenny State Fish Hatchery. 


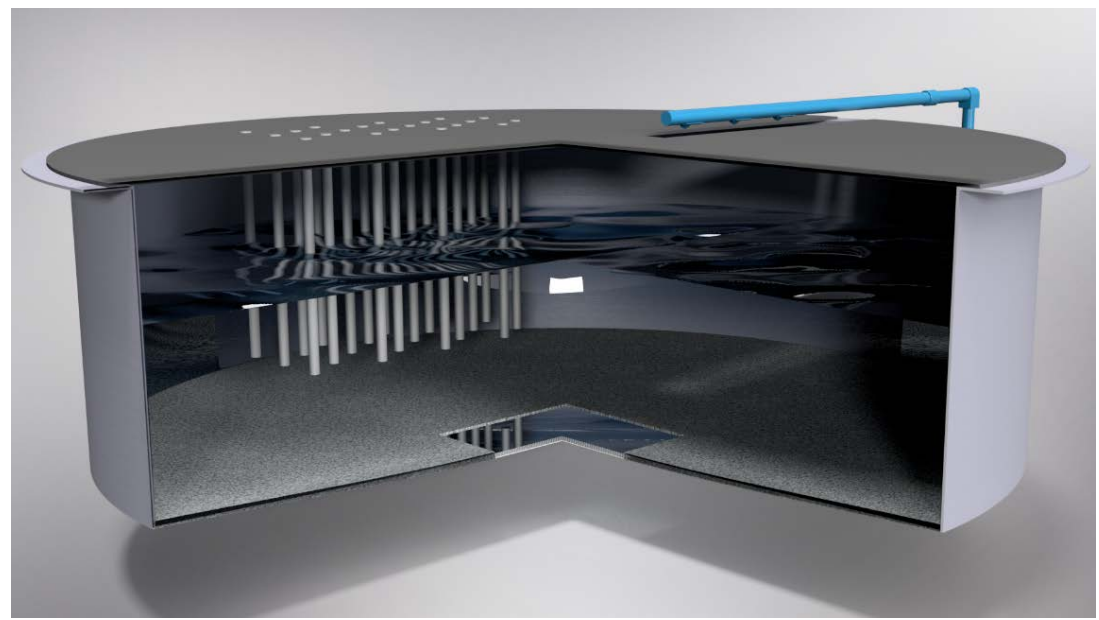

Figure 3. Model of the circular tank interior with a view of vertically-suspended structure array.

Table 1. Scenarios for sampling velocities in a circular tank with and without vertically-suspended structure with or without the presence of fish at two densities.

\begin{tabular}{ccc}
\hline Scenario & Structure & Fish \\
\hline 1 & No & None \\
2 & No & Low density \\
3 & No & High density \\
4 & Yes & None \\
5 & Yes & Low density \\
6 & Yes & High density \\
\hline
\end{tabular}

To measure in-tank velocities, a grid system was overlaid on the overhead view of the tank (Figure 4). The $0^{\circ}$ axis was the location of the horizontal spray bar and the $90^{\circ}$ axis was the location of enrichment structure. On each axis $\left(0^{\circ}\right.$, $90^{\circ}, 180^{\circ}$, and $270^{\circ}$ ), velocity samples were taken at three locations: near the edge of the tank, in the middle of the axis, and near the central drain. At each of these locations, data was collected at three depths: near the top of the water column, in the middle, and near the bottom (Figure 5; Table 2). Two replicates for each sampling location were recorded. Velocity measurements were taken with a JDC Electronics Flowatch Flowmeter (JDC, Yverdon-les-Bains, Switzerland).

In addition to collecting velocity data with or without the presence of vertically-suspended structure, sampling also occurred with or without the presence of fish at two different densities. At the first sampling date (March 31, 2020), the tank contained 9.3-cm long (total length) landlocked fall Chinook salmon (Oncorhynchus tshawytscha) at a density of $9.0 \mathrm{~kg} / \mathrm{m}^{3}$. Sampling occurred again on June 3, 2020 when the same fish had grown to approximately $13.8-\mathrm{cm}$ long and the tank density was $34.3 \mathrm{~kg} / \mathrm{m}^{3}$. Thus, the two densities did not contain the same size of fish; fish size increased as density increased. 


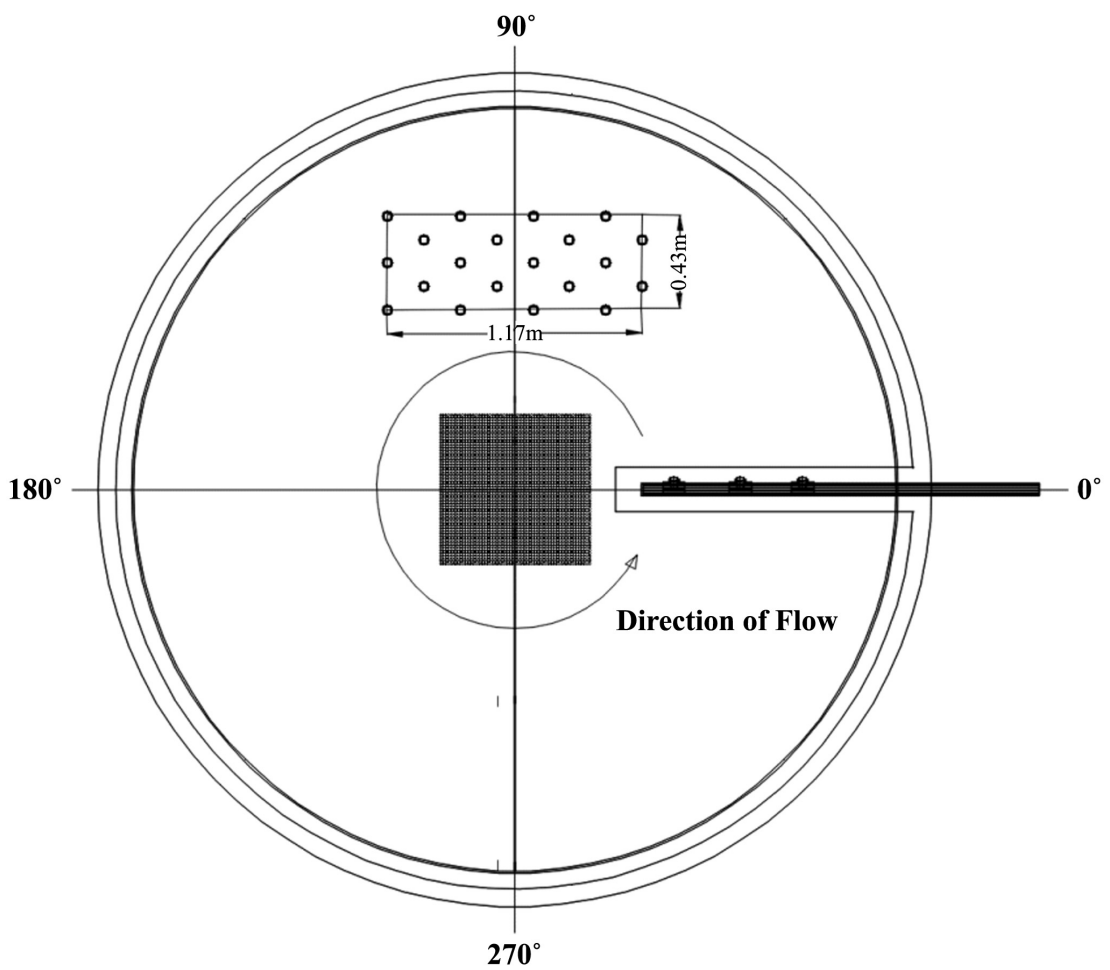

Figure 4. Overhead view of the salmon rearing tank showing sampling location degrees and array size.

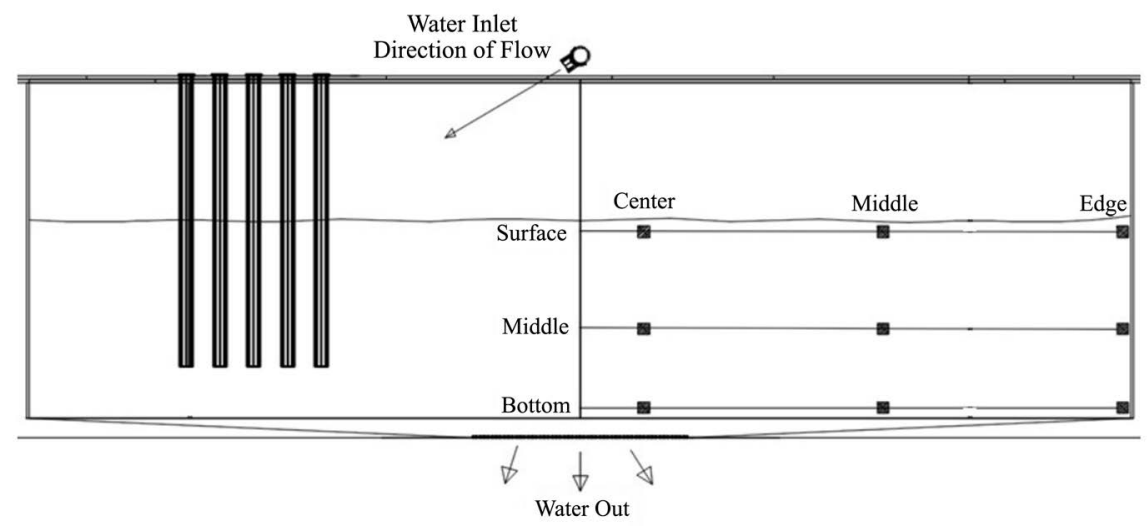

Figure 5. Cross-sectional view of the salmon rearing tank with sampling locations.

Table 2. Velocity sampling locations.

\begin{tabular}{ccc}
\hline & & Distance $(\mathrm{cm})$ \\
\hline Radial position $^{\mathrm{a}}$ & Center & 20 \\
& Middle & 122 \\
& Edge & 173 \\
Depth $^{\mathrm{b}}$ & Surface & 4 \\
& Middle & 35 \\
& Bottom & 66 \\
\hline
\end{tabular}

${ }^{\mathrm{a} D i s t a n c e}$ is from midpoint of water column; ${ }^{\mathrm{b}}$ Distance is from surface of water column. 
Data were initially analyzed by analysis of variance and covariance using the SPSS (24.0) statistical analysis program (IBM, Armonk, New York, USA). Because of the large number of interactions, subsequent analysis used one-way analysis of variance. Tukey's mean comparison procedure was used for post-hoc analysis. The significance level for all tests was predetermined at $\mathrm{P}<0.05$.

\section{Results}

The addition of vertically-suspended structure to the tank significantly decreased velocities at nearly every sampling point. Specifically, velocities at the three radial locations were at least $15 \mathrm{~cm} / \mathrm{s}$ in the absence of structure but decreased to less than $6 \mathrm{~cm} / \mathrm{s}$ when structure was present (Table 3). Fish density also significantly impacted in-tank velocities. In general, an inverse relationship between the density of fish and water velocity was observed (Table 4). Significant interactions were observed among the presence or absence of structure and fish density. When structure and fish were absent, an edge velocity of $15.63 \mathrm{~cm} / \mathrm{s}$ was observed, which was significantly higher than the $4.75 \mathrm{~cm} / \mathrm{s}$ velocity when structure was added at the lower fish density (Table 5). This in turn was significantly higher than the $2.29 \mathrm{~cm} / \mathrm{s}$ velocity observed with structure and higher fish density. At the fish density of $9.0 \mathrm{~kg} / \mathrm{m}^{3}$, cross-sectional profiles of the circular tank indicated reduced velocities at each depth with the presence of structure in comparison to the absence of either fish or structure, the presence of only fish, or the presence of both fish and structure (Figures 6-11). In contrast, the combination of both structure and fish produced the slowest velocity profiles at the fish density of $34.3 \mathrm{~kg} / \mathrm{m}^{3}$, with slightly higher velocities observed with just the presence of structure in Figures 12-17. The highest velocities occurred with either the presence of only fish or the absence of both fish and structure.

Table 3. Mean $( \pm S D)$ overall water velocities $(\mathrm{cm} / \mathrm{s})$ at three radial positions in a circular tank with or without vertically-suspended structures, all sampling depths combined. Means with different letters in same columns are significantly different $(\mathrm{P}<0.05)$.

\begin{tabular}{cccc}
\hline \multirow{2}{*}{ Structure } & \multicolumn{3}{c}{ Radial position } \\
\cline { 2 - 4 } & Center & Middle & Edge \\
\hline Absent & $20.04 \pm 4.35 \mathrm{z}$ & $22.88 \pm 2.77 \mathrm{z}$ & $15.63 \pm 2.22 \mathrm{z}$ \\
Present & $4.75 \pm 2.64 \mathrm{y}$ & $5.71 \pm 2.56 \mathrm{y}$ & $4.75 \pm 2.33 \mathrm{y}$ \\
\hline
\end{tabular}

Table 4. Mean $( \pm S D)$ overall water velocities $(\mathrm{cm} / \mathrm{s})$ at three radial positions in a circular tank with three different fish densities, all sampling depths combined. Means with different letters in same column are significantly different $(\mathrm{P}<0.05)$.

\begin{tabular}{cccc}
\hline \multirow{2}{*}{ Fish } & \multicolumn{3}{c}{ Radial position } \\
\cline { 2 - 4 } & Center & Middle & Edge \\
\hline Absent & $20.04 \pm 4.35 \mathrm{z}$ & $22.88 \pm 2.77 \mathrm{z}$ & $15.63 \pm 2.22 \mathrm{z}$ \\
$9.0 \mathrm{~kg} / \mathrm{m}^{3}$ & $17.33 \pm 4.68 \mathrm{z}$ & $17.25 \pm 3.05 \mathrm{y}$ & $11.21 \pm 1.91 \mathrm{y}$ \\
$34.3 \mathrm{~kg} / \mathrm{m}^{3}$ & $10.25 \pm 2.54 \mathrm{y}$ & $14.38 \pm 4.52 \mathrm{x}$ & $15.25 \pm 4.53 \mathrm{z}$ \\
\hline
\end{tabular}


Table 5. Mean $( \pm S D)$ overall water velocities $(\mathrm{cm} / \mathrm{s})$ at three radial positions in a circular tank, with and without vertically-suspended structure, and three different fish densities, all sampling depths combined. Means with different letters in the same column are significantly different $(\mathrm{P}<0.05)$.

\begin{tabular}{ccccc}
\hline \multirow{2}{*}{ Fish } & Structure & \multicolumn{3}{c}{ Radial position } \\
\cline { 3 - 4 } & & Center & Middle & Edge \\
\hline Absent & Absent & $20.04 \pm 4.35 \mathrm{z}$ & $22.88 \pm 2.77 \mathrm{z}$ & $15.63 \pm 2.22 \mathrm{z}$ \\
$9.0 \mathrm{~kg} / \mathrm{m}^{3}$ & Present & $4.75 \pm 2.64 \mathrm{y}$ & $5.71 \pm 2.56 \mathrm{y}$ & $4.75 \pm 2.33 \mathrm{y}$ \\
$34.3 \mathrm{~kg} / \mathrm{m}^{3}$ & Present & $3.92 \pm 2.04 \mathrm{y}$ & $4.13 \pm 1.87 \mathrm{y}$ & $2.29 \pm 1.97 \mathrm{x}$ \\
\hline
\end{tabular}

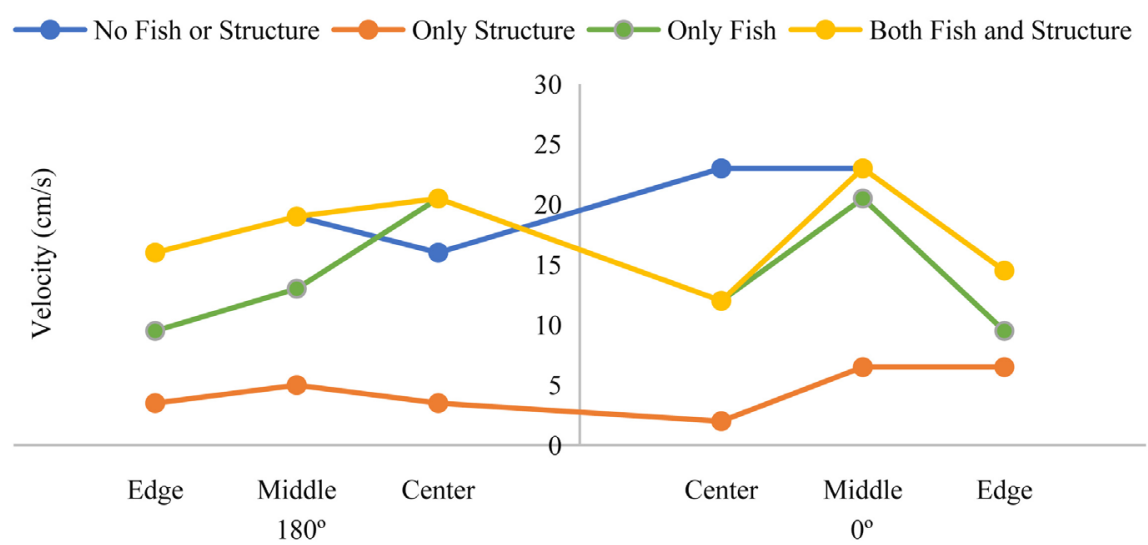

Figure 6. Cross-sectional velocity profiles at a depth of $4 \mathrm{~cm}$ (surface) of a $3.63-\mathrm{m} \mathrm{di}$ ameter circular tank parallel to the incoming water supply (spray bar-location 0 ) and across to the other side of the tank (location 180). Sampling locations from the center of the tank were $20 \mathrm{~cm}$ (Center), $122 \mathrm{~cm}$ (Middle), and $173 \mathrm{~cm}$ (Edge-2 cm from the outer edge of the tank). Velocities were recorded with the tank void of fish or structure, with the tank containing either fish at a density of $9.0 \mathrm{~kg} / \mathrm{m}^{3}$ or an array of vertically-suspended structure, or with the tank containing both fish and structure.

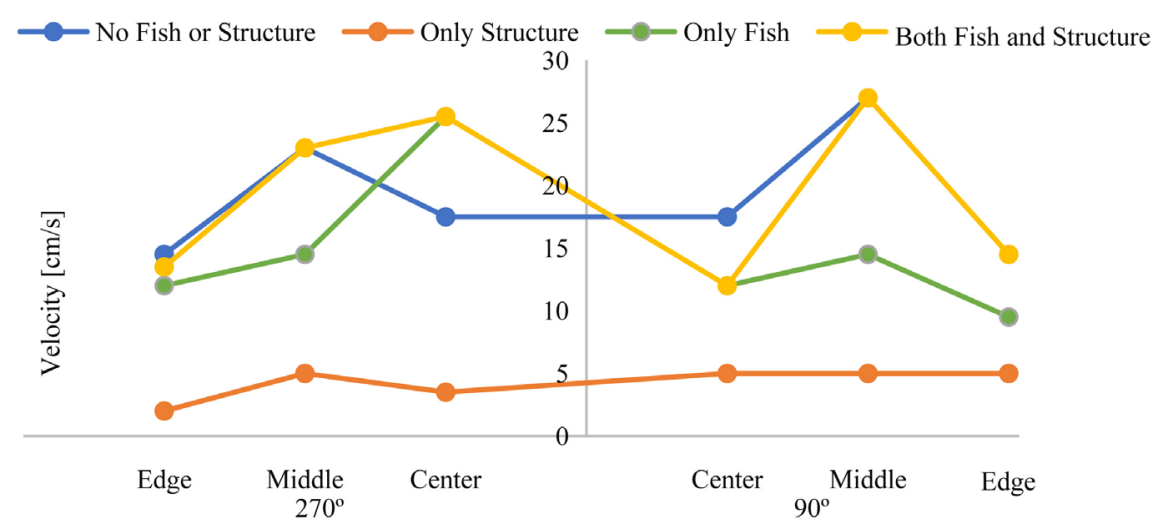

Figure 7. Cross-sectional velocity profiles at a depth of $4 \mathrm{~cm}$ (surface) of a $3.63-\mathrm{m} \mathrm{di-}$ ameter circular tank perpendicular to the incoming water supply from the location of an array of vertically-suspended structure (location 90) and across to the other side of the tank (location 270). Sampling locations from the center of the tank were $20 \mathrm{~cm}$ (Center), $122 \mathrm{~cm}$ (Middle), and $173 \mathrm{~cm}$ (Edge $-2 \mathrm{~cm}$ from the outer edge of the tank). Velocities were recorded with the tank void of fish or structure, with the tank containing either fish at a density of $9.0 \mathrm{~kg} / \mathrm{m}^{3}$ or structure, or with the tank containing both fish and structure. 


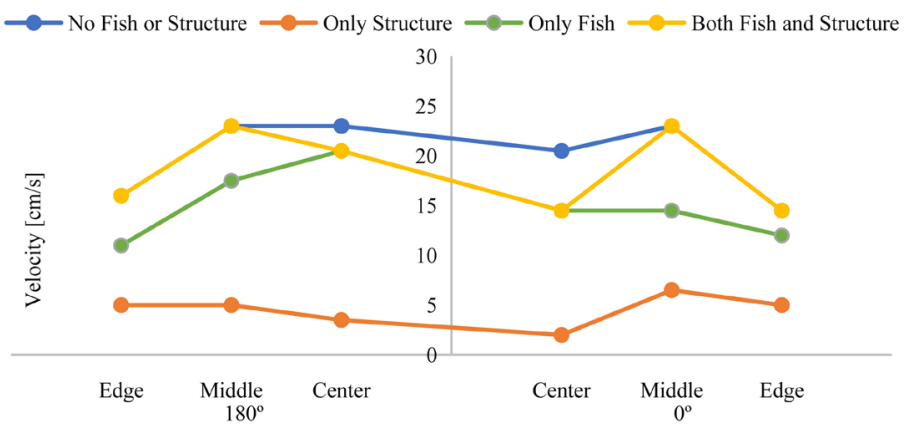

Figure 8. Cross-sectional velocity profiles at a depth of $35 \mathrm{~cm}$ (middle level) of a 3.63-m diameter circular tank parallel to the incoming water supply (spray bar-location 0 ) and across to the other side of the tank (location 180). Sampling locations from the center of the tank were $20 \mathrm{~cm}$ (Center), $122 \mathrm{~cm}$ (Middle), and $173 \mathrm{~cm}$ (Edge $-2 \mathrm{~cm}$ from the outer edge of the tank). Velocities were recorded with the tank void of fish or structure, with the tank containing either fish at a density of $9.0 \mathrm{~kg} / \mathrm{m}^{3}$ or an array of vertically-suspended structure, or with the tank containing both fish and structure.

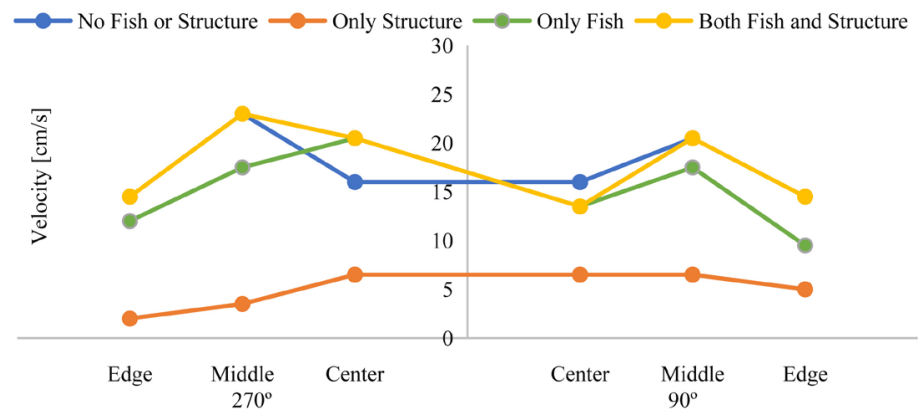

Figure 9. Cross-sectional velocity profiles at a depth of $35 \mathrm{~cm}$ (middle level) of a $3.63-\mathrm{m}$ diameter circular tank perpendicular to the incoming water supply from the location of an array of vertically-suspended structure (location 90) and across to the other side of the tank (location 270). Sampling locations from the center of the tank were $20 \mathrm{~cm}$ (Center), $122 \mathrm{~cm}$ (Middle), and $173 \mathrm{~cm}$ (Edge $-2 \mathrm{~cm}$ from the outer edge of the tank). Velocities were recorded with the tank void of fish or structure, with the tank containing either fish at a density of $9.0 \mathrm{~kg} / \mathrm{m}^{3}$ or structure, or with the tank containing both fish and structure.

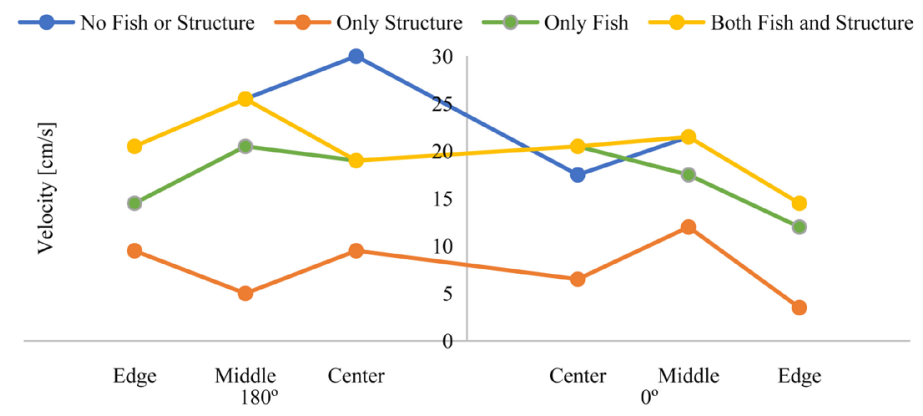

Figure 10. Cross-sectional velocity profiles at a depth of $66 \mathrm{~cm}$ (bottom) of a $3.63-\mathrm{m} \mathrm{di}$ ameter circular tank parallel to the incoming water supply (spray bar-location 0 ) and across to the other side of the tank (location 180). Sampling locations from the center of the tank were $20 \mathrm{~cm}$ (Center), $122 \mathrm{~cm}$ (Middle), and $173 \mathrm{~cm}$ (Edge $-2 \mathrm{~cm}$ from the outer edge of the tank). Velocities were recorded with the tank void of fish or structure, with the tank containing either fish at a density of $9.0 \mathrm{~kg} / \mathrm{m}^{3}$ or an array of vertically-suspended structure, or with the tank containing both fish and structure. 


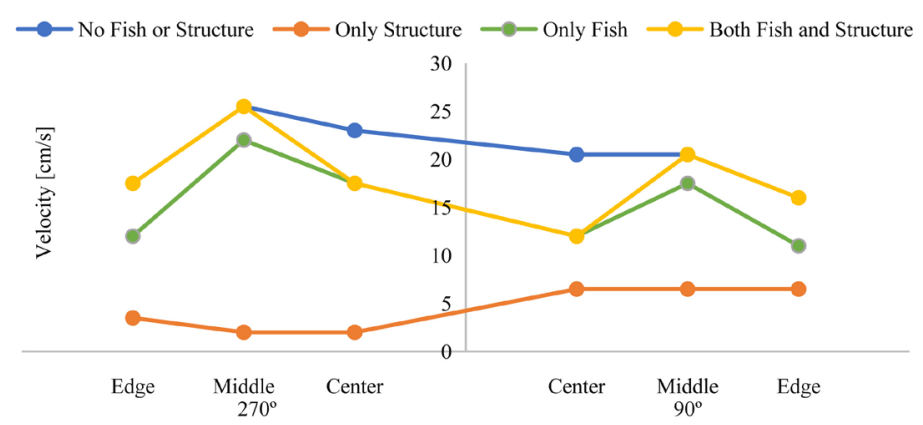

Figure 11. Cross-sectional velocity profiles at a depth of $66 \mathrm{~cm}$ (bottom) of a 3.63-m diameter circular tank perpendicular to the incoming water supply from the location of an array of vertically-suspended structure (location 90) and across to the other side of the tank (location 270). Sampling locations from the center of the tank were $20 \mathrm{~cm}$ (Center), $122 \mathrm{~cm}$ (Middle), and $173 \mathrm{~cm}$ (Edge-2 $\mathrm{cm}$ from the outer edge of the tank). Velocities were recorded with the tank void of fish or structure, with the tank containing either fish at a density of $9.0 \mathrm{~kg} / \mathrm{m}^{3}$ or structure, or with the tank containing both fish and structure.

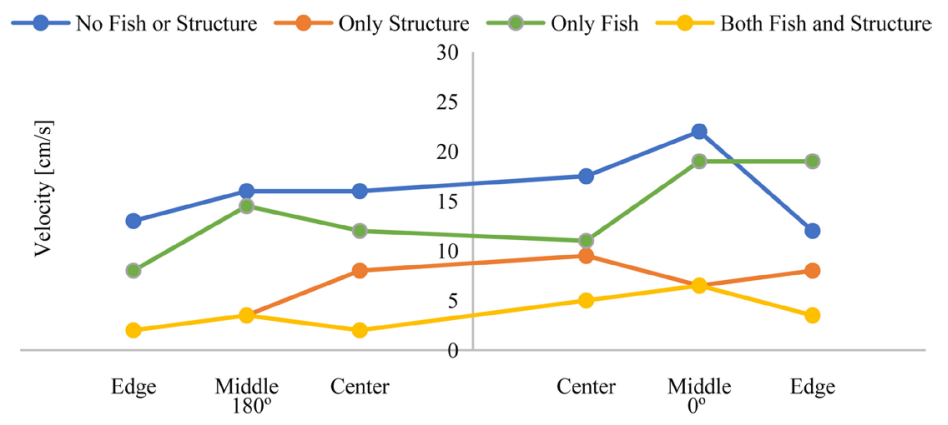

Figure 12. Cross-sectional velocity profiles at a depth of $4 \mathrm{~cm}$ (surface) of a $3.63-\mathrm{m} \mathrm{di}$ ameter circular tank parallel to the incoming water supply (spray bar-location 0 ) and across to the other side of the tank (location 180). Sampling locations from the center of the tank were $20 \mathrm{~cm}$ (Center), $122 \mathrm{~cm}$ (Middle), and $173 \mathrm{~cm}$ (Edge-2 cm from the outer edge of the tank). Velocities were recorded with the tank void of fish or structure, with the tank containing either fish at a density of $34.3 \mathrm{~kg} / \mathrm{m}^{3}$ or an array of vertically-suspended structure, or with the tank containing both fish and structure.

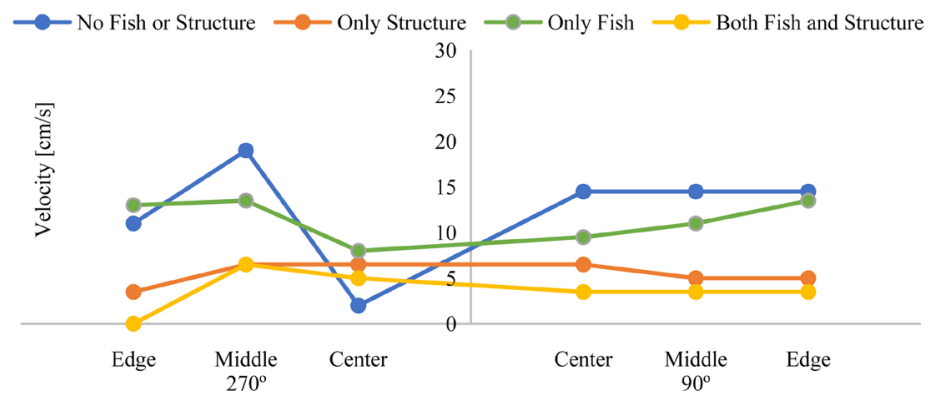

Figure 13. Cross-sectional velocity profiles at a depth of $4 \mathrm{~cm}$ (surface) of a $3.63-\mathrm{m} \mathrm{di}$ ameter circular tank perpendicular to the incoming water supply from the location of an array of vertically-suspended structure (location 90) and across to the other side of the tank (location 270). Sampling locations from the center of the tank were $20 \mathrm{~cm}$ (Center), $122 \mathrm{~cm}$ (Middle), and $173 \mathrm{~cm}$ (Edge $-2 \mathrm{~cm}$ from the outer edge of the tank). Velocities were recorded with the tank void of fish or structure, with the tank containing either fish at a density of $34.3 \mathrm{~kg} / \mathrm{m}^{3}$ or structure, or with the tank containing both fish and structure. 


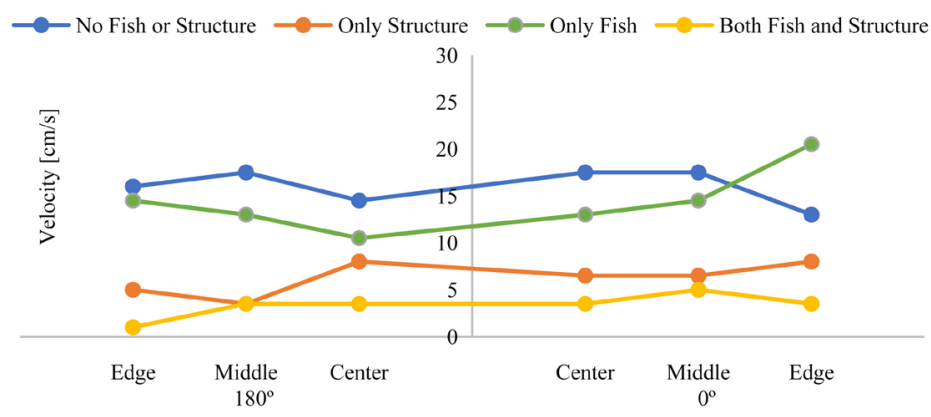

Figure 14. Cross-sectional velocity profiles at a depth of $35 \mathrm{~cm}$ (middle level) of a 3.63-m diameter circular tank parallel to the incoming water supply (spray bar-location 0 ) and across to the other side of the tank (location 180). Sampling locations from the center of the tank were $20 \mathrm{~cm}$ (Center), $122 \mathrm{~cm}$ (Middle), and $173 \mathrm{~cm}$ (Edge $-2 \mathrm{~cm}$ from the outer edge of the tank). Velocities were recorded with the tank void of fish or structure, with the tank containing either fish at a density of $34.3 \mathrm{~kg} / \mathrm{m}^{3}$ or an array of vertically-suspended structure, or with the tank containing both fish and structure.

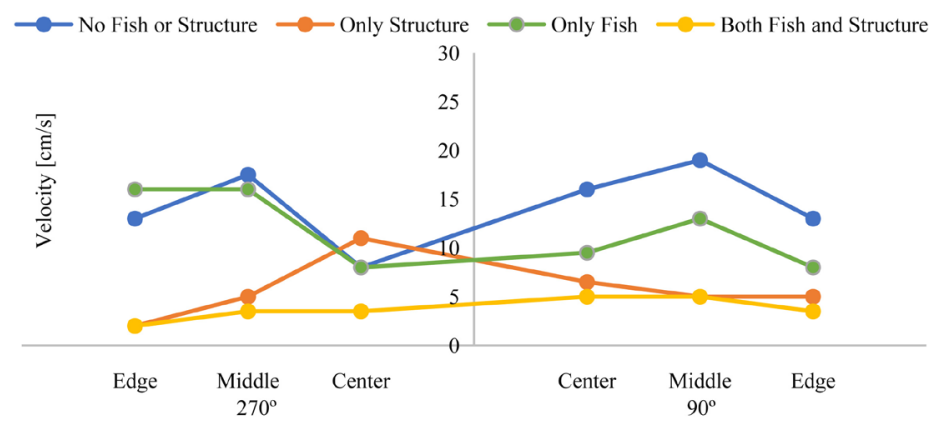

Figure 15. Cross-sectional velocity profiles at a depth of $35 \mathrm{~cm}$ (middle level) of a 3.63-m diameter circular tank perpendicular to the incoming water supply from the location of an array of vertically-suspended structure (location 90) and across to the other side of the tank (location 270). Sampling locations from the center of the tank were $20 \mathrm{~cm}$ (Center), $122 \mathrm{~cm}$ (Middle), and $173 \mathrm{~cm}$ (Edge-2 cm from the outer edge of the tank). Velocities were recorded with the tank void of fish or structure, with the tank containing either fish at a density of $34.3 \mathrm{~kg} / \mathrm{m}^{3}$ or structure, or with the tank containing both fish and structure.

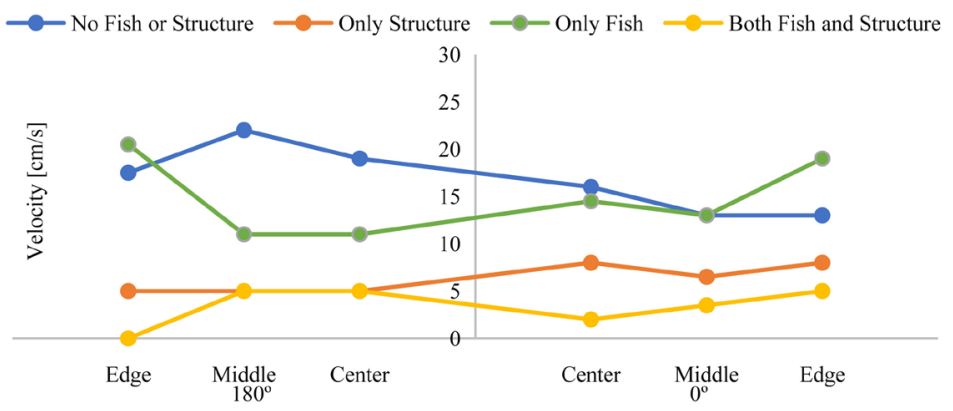

Figure 16. Cross-sectional velocity profiles at a depth of $66 \mathrm{~cm}$ (bottom) of a 3.63-m diameter circular tank parallel to the incoming water supply (spray bar-location 0 ) and across to the other side of the tank (location 180). Sampling locations from the center of the tank were $20 \mathrm{~cm}$ (Center), $122 \mathrm{~cm}$ (Middle), and $173 \mathrm{~cm}$ (Edge $-2 \mathrm{~cm}$ from the outer edge of the tank). Velocities were recorded with the tank void of fish or structure, with the tank containing either fish at a density of $34.3 \mathrm{~kg} / \mathrm{m}^{3}$ or an array of vertically-suspended structure, or with the tank containing both fish and structure. 


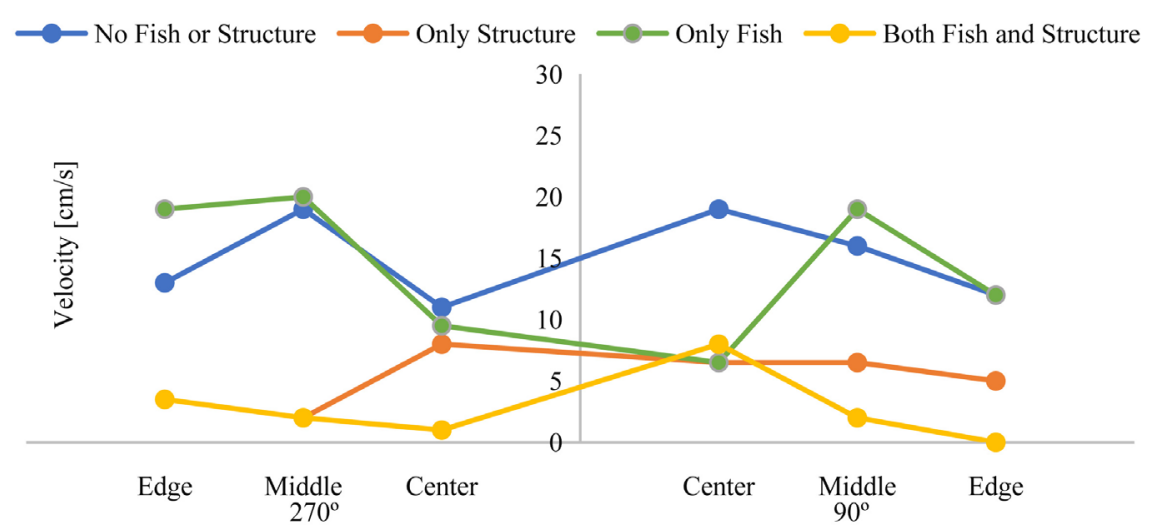

Figure 17. Cross-sectional velocity profiles at a depth of $66 \mathrm{~cm}$ (bottom) of a 3.63-m diameter circular tank perpendicular to the incoming water supply from the location of an array of vertically-suspended structure (location 90) and across to the other side of the tank (location 270). Sampling locations from the center of the tank were $20 \mathrm{~cm}$ (Center), $122 \mathrm{~cm}$ (Middle), and $173 \mathrm{~cm}$ (Edge $-2 \mathrm{~cm}$ from the outer edge of the tank). Velocities were recorded with the tank void of fish or structure, with the tank containing either fish at a density of $34.3 \mathrm{~kg} / \mathrm{m}^{3}$ or structure, or with the tank containing both fish and structure.

\section{Discussion}

In the absence of structure or fish, the velocity profile of the circular tank follows the pattern described by Timmons et al. [1] and Sumida et al. [37] of a large central vortex and irrotational zone. These features are instrumental in creating the self-cleaning nature of circular tanks during fish rearing. However, reductions in water velocity can hinder this beneficial self-cleaning [11] [36]. Lekang [11] suggests that if water velocity at the bottom of the tank is below $8 \mathrm{~cm} / \mathrm{s}$, the self-cleaning effect is nonexistent. The presence of structure in the tank, and particularly the presence of both structure and either of the fish densities produced velocities at or below this threshold. However, Lekang [11] also suggests that at higher fish densities, lower velocities could be acceptable because fish movement increases resuspension of solids to allow the secondary flow pattern to carry particles to the drain. Unlike Lekang [11], velocities in the present study were not highest at the edge of the tank. Nor was there a consistent trend of higher velocities at the top of the tank.

The reduction in water velocity resulting from the placement of structure in the tank in this study supports the observations of Moine et al. [14] and Muggli et al. [15]. However, there is a difference in velocity-reduction magnitude. Moine et al. [14] and Muggli et al. [15] reported that structure decreased the overall tank velocity from highs of 21 to $24 \mathrm{~cm} / \mathrm{s}$ to as low as 0 to $3 \mathrm{~cm} / \mathrm{s}$. In contrast, this study had high velocities of 17 to $20 \mathrm{~cm} / \mathrm{s}$ which decreased in the presence of structure down to as low as 4 to $7 \mathrm{~cm} / \mathrm{s}$. The differences between this study and Moine et al. [14] and Muggli et al. [15] could be due to differences in the structural arrays used and the size of the circular tanks. This study used longer rods in a 20-rod array in a 3.63-m diameter tank, compared to the shorter nine-rod and 15-rod arrays in 1.8-m tanks used by Moine et al. [14] and Muggli et al. [15]. 
This study confirms the reduction of tank velocities with the presence of fish as described by Plew et al. [12] and Oca and Masalo [36]. In this study, average tank velocity was reduced by $25 \%$ at the lower density of $9 \mathrm{~kg} / \mathrm{m}^{3}$ and $10 \%$ at the higher density of $34.3 \mathrm{~kg} / \mathrm{m}^{3}$. Plew et al. [12] reported a $15 \%$ reduction in velocity at stocking densities of $15.3 \mathrm{~kg} / \mathrm{m}^{3}$ and $35.6 \mathrm{~kg} / \mathrm{m}^{3}$, and a $57 \%$ reduction at $79.4 \mathrm{~kg} / \mathrm{m}^{3}$. However, Oca and Masalo [36] reported a significant loss in velocity in the center of the tank at a stocking density of $14 \mathrm{~kg} / \mathrm{m}^{3}$. No such velocity loss was observed in this study. This discrepancy could possibly be because of differences in the tank sizes and fish densities used. Plew et al. [12] used considerably larger, 15-m diameter tanks, whereas Oca and Masalo [36] used smaller, 1.44-m diameter tanks containing fewer fish. In addition, compared to the present investigation, Oca and Masalo [36] examined in-tank velocities in much more detail than the present study.

The effect of fish density is greatly impacted by the presence of structure. In this study, at a fish density of $9.0 \mathrm{~kg} / \mathrm{m}^{3}$ water velocity remains virtually unchanged, if not slightly slower. However, when the density is increased to 34.3 $\mathrm{kg} / \mathrm{m}^{3}$, velocity is reduced drastically. Fausch [38] indicated that fish are more likely to dwell in the lower velocity regions of the tank during non-feeding periods, thereby avoiding the higher-velocity, more energy-intensive areas where food becomes available. It is likely that the fish associate with the lower-velocity areas of the vertically-suspended structure, and at higher fish densities, the combination of fish and structure becomes almost like a wall impeding water flow. In other words, the more fish that congregate next to the structure, the more impact they will have in reducing the tank velocity, and this effect would be multiplied at higher densities. The results from the present study support this hypothesis.

The positive effects of vertically-suspended environmental enrichment structures on fish growth are well documented [28] [29] [30] [31] [33] [35]. It is likely that at least some of these positive effects occur because of the reduction in water velocities. Although high-velocity-induced exercise can benefit fish growth in the short term [5] [6] [39] [40] [41] [42], long periods of exercise can be harmful [7] [8]. Thus, by providing non-uniform with-in tank velocities, the suspended structures are likely providing refuge areas from continual exercise and also allowing the fish to minimize their energy expenditures during feeding [38]. By altering within-tank velocities, vertically-suspended structures may also be improving fish growth by providing more uniform oxygen concentrations throughout the tank [43]. Although dissolved oxygen levels are relatively uniform in circular tanks, particularly in comparison to rectangular fish rearing tanks [2] [3]; there is still variation in dissolved oxygen levels throughout circular tanks [10] [12] [13].

The results of this study may be unique to the size of tank, spray bar configuration, and suspended structure used, as well as by the size and species of fish. Tvinnereim and Skybakmoen [9], Davidson and Summerfelt [10], Oca and Masalo [3], Plew et al. [12], Gorle et al. [13], and Muggli et al. [15] all indicate that 
circular tank velocity profiles can be influenced by multiple factors, including tank size, water inlets and outlets, incoming water velocities, number and size of fish in the tank, and type and size of suspended enrichment structure. However, despite the potentially unique features of this study, vertically-suspended environmental enrichment and the presence of fish clearly decrease circular tank water velocities.

\section{Conclusion}

This study using a specific size of circular tank demonstrated that a unique form of environmental enrichment and two distinct fish densities can act alone and also interact to dramatically alter within tank water velocity profiles. These changes in water velocity affect the hydraulic self-cleaning of the circular tank and may at least partially explain the improvements in fish rearing performance observed with the use of suspended structures.

\section{Acknowledgements}

Thanks to Edgar Meza, Benj Morris, Lauren Van Rysselberge, Nathan Huysman, Jill Voorhees, Eric Krebs, and Barry Hanson for their assistance with this investigation.

\section{Conflicts of Interest}

The authors declare no conflicts of interest regarding the publication of this paper.

\section{References}

[1] Timmons, M.B., Summerfelt, S.T. and Vinci, B.J. (1998) Review of Circular Tank Technology and Management. Aquacultural Engineering, 18, 51-69. https://doi.org/10.1016/S0144-8609(98)00023-5

[2] Duarte S., Reig, L., Masalo, I., Blanco, M. and Oca, J. (2011) Influence of Tank Geometry and Flow Pattern in Fish Distribution. Aquacultural Engineering, 44, 48-54. https://doi.org/10.1016/j.aquaeng.2010.12.002

[3] Oca, J. and Masalo, I. (2013) Flow Pattern in Aquaculture Circular Tanks: Influence of Flow Rate, Water Depth, and Water Inlet \& Outlet Features. Aquacultural Engineering, 52, 65-72. https://doi.org/10.1016/j.aquaeng.2012.09.002

[4] Ross, R.M. and Watten, B.J. (1998) Importance of Rearing-Unit Design and Stocking Density to the Behavior, Growth and Metabolism of Lake Trout (Salvelinus namaycush). Aquaculutre Egnineering, 19, 41-56. https://doi.org/10.1016/S0144-8609(98)00041-7

[5] Parker, T.M. and Barnes, M.E. (2014) Rearing Velocity Impacts on Landlocked Fall Chinook Salmon (Oncorhynchus tshawytscha) Growth, Condition, and Survival. Open Journal of Animal Sciences, 4, 244-252. https://doi.org/10.4236/ojas.2014.45031

[6] Parker, T.M. and Barnes, M.E. (2015) Effects of Different Water Velocities on the Hatchery Rearing Performance and Recovery from Transportation of Rainbow Trout Fed Two Different Rations. Transactions of the American Fisheries Society, 144, 882-890. https://doi.org/10.1080/00028487.2015.1047533 
[7] Voorhees, J.M., Barnes, M.E., Chipps, S.R. and Brown, M.L. (2018) Dietary Bioprocessed Soybean Meal Does Not Affect the Growth of Exercised Rainbow Trout (Oncorhynchus mykiss). Journal of Animal Research and Nutrition, 3, Article ID: 1579482. https://doi.org/10.1080/23311932.2019.1579482

[8] Voorhees, J.M., Barnes, M.E., Chipps, S.R. and Brown, M.L. (2018) Rearing Performance of Juvenile Brown Trout (Salmo trutta) Subjected to Exercise and Dietary Bioprocessed Soybean Meal. Open Journal of Animal Sciences, 8, 303-328.

https://doi.org/10.4236/ojas.2018.83023

[9] Tvinnereim, K. and Skybakmoen, S. (1989) Water Exchange and Self-Cleaning in Fish Rearing Tanks. In: De Pauw, N., Jaspers, E., Ackefors, H. and Wilkens, N., Eds., Aquaculture: A Biotechnology in Progress, European Aquaculture Society, Bredena, 1041-1047.

[10] Davidson, J. and Summerfelt, S. (2004) Solids Flushing, Mixing, and Water Velocity Profiles within Large $\left(10\right.$ and $150 \mathrm{~m}^{3}$ ) Circular Cornell-Type Dual-Drain Tanks. Aquacultural Engineering, 32, 245-271. https://doi.org/10.1016/j.aquaeng.2004.03.009

[11] Lekang, O.-I. (2013) Aquaculture Engineering. 2nd Edition, Wiley-Blackwell, Chichester. https://doi.org/10.1002/9781118496077

[12] Plew, D.R., Klebert, P., Rosten, T.W., Aspaas, S. and Birkevold, J. (2015) Change to Flow and Turbulence Caused by Different Concentrations of Fish in a Circular Tank. Journal of Hydraulic Research, 53, 364-383. https://doi.org/10.1080/00221686.2015.1029016

[13] Gorle, J.M.R., Terjesen B.F. and Summerfelt, S.F. (2018) Hydrodynamics of Octagonal Culture Tanks with Cornell-Type Dual-Drain System. Computers and Electronics in Agriculture, 151, 354-364. https://doi.org/10.1016/j.compag.2018.06.012

[14] Moine, J., Barnes M.E., Kientz J. and Simpson G. (2016) Flow Patterns in Circular Rearing Tanks Containing Vertical Structure. Journal of Fisheries and Livestock Production, 4, 204. https://doi.org/10.4172/2332-2608.1000204

[15] Muggli, A.M., Barnes, J.M. and Barnes, M.E. (2019) Vertically-Suspended Environmental Enrichment Alters the Velocity Profiles of Circular Fish Rearing Tanks. World Journal of Engineering and Technology, 7, 208-226. https://doi.org/10.4236/wjet.2019.71014

[16] Naslund, J. and Johnsson, J.I. (2016) Environmental Enrichment for Fish in Captive Environments: Effects of Physical Structures and Substrates. Fish and Fisheries, 17, 1-30. https://doi.org/10.1111/faf.12088

[17] Berejikian, B.A., Smith, R.J.F., Tezak, E.P., Schroder, S.L. and Knudsen, C.M. (1999) Chemical Alarm Signals and Complex Hatchery Rearing Habitats Affect Antipredator Behavior and Survival of Chinook Salmon (Oncorhynchus tshawytscha) Juveniles. Canadian Journal of Fisheries and Aquatic Sciences, 56, 830-838.

https://doi.org/10.1139/f99-010

[18] Berejikian, B.A., Tezak, E.P., Flagg, T.A., LaRae, A.L., Kummerow, E. and Mahnken, C.V.W. (2000) Social Dominance, Growth, and Habitat Use of Age-0 Steelhead Oncorhynchus mykiss Grown in Enriched and Conventional Hatchery Rearing Environments. Canadian Journal of Fisheries and Aquatic Sciences, 57, 628-636. https://doi.org/10.1139/f99-288

[19] Brown, C., Davidson, T. and Laland, K. (2003) Environmental Enrichment and Prior Experience of Live Prey Improve Foraging Behaviour in Hatchery-Reared Atlantic Salmon. Journal of Fish Biology, 63, 187-196. https://doi.org/10.1111/j.1095-8649.2003.00208.x 
[20] Berejikian, B.A. and Tezak, E.P. (2005) Rearing in Enriched Hatchery Tanks Improves Dorsal Fin Quality of Juvenile Steelhead. North American Journal of Aquaculture, 67, 289-293. https://doi.org/10.1577/A05-002.1

[21] Brockmark, S., Neregard, L., Bohlin, T., Bjornsson, B.T. and Johnsson, J.I. (2007) Effects of Rearing Density and Structural Complexity on Pre- and Postrelease Performance of Atlantic Salmon. Transactions of the American Fisheries Society, 136, 1453-1462. https://doi.org/10.1577/T06-245.1

[22] Fast, D.E., Neeley, D., Lind, D.T., Johnston, M.V., Strom, C.R., Bosch, W.J., Knudsen, C.M., Schroder, S.L. and Watson, B.D. (2008) Survival Comparison of Spring Chinook Salmon Reared in a Production Hatchery under Optimum Conventional and Seminatural Conditions. Transactions of the American Fisheries Society, 137, 1507-1518. https://doi.org/10.1577/T07-143.1

[23] Bergendahl, A.I., Miller, S., Depasquale, C., Giralico, L. and Braithwaite, V.A. (2017) Becoming a Better Swimmer: Structural Complexity Enhances Agility in Captive-Reared Fish. Journal of Fish Biology, 90, 1112-1117. https://doi.org/10.1111/jfb.13232

[24] Krebs, J., Crank, K.M., Krebs, E. and Barnes, M.E. (2017) Use of Bottom Structure and Tank Cover during Rainbow Trout Rearing in Circular Tanks. Journal of Fisheries and Livestock Production, 5, Article ID: 1000247. https://doi.org/10.4172/2332-2608.1000247

[25] Baynes, S.M. and Howell, B.R. (1993) Observations on the Growth, Survival and Disease Resistance of Juvenile Common Sole, Solea solea L. Aquaculture and Fisheries Management, 24, 95-100. https://doi.org/10.1111/j.1365-2109.1993.tb00831.x

[26] Tuckey, L.M. and Smith, T.I. (2001) Effects of Photoperiod and Substrate on Larval Development and Substrate Preference of Juvenile Southern Flounder, Paralichthys lethostigma. Journal of Applied Aquaculture, 11, 1-20. https://doi.org/10.1300/J028v11n01_02

[27] Oca, J. and Masalo, I. (2007) Design Criteria for Rotating Flow Cells in Rectangular Aquaculture Tanks. Aquacultural Engineering, 36, 36-44. https://doi.org/10.1016/j.aquaeng.2006.06.001

[28] Kientz, J.L. and Barnes, M.E. (2016) Structural Complexity Improves the Rearing Performance of Rainbow Trout in Circular Tanks. North American Journal of Aquaculture, 78, 203-207. https://doi.org/10.1080/15222055.2016.1159629

[29] Kientz, J.L., Crank, K.M. and Barnes, M.E. (2018) Enrichment of Circular Tanks with Vertically Suspended Strings of Colored Balls Improves Rainbow Trout Rearing Performance. North American Journal of Aquaculture, 80, 162-167. https://doi.org/10.1002/naaq.10017

[30] Krebs, E., Huysman, N., Voorhees, J.M. and Barnes, M.E. (2018) Suspended Arrays Improve Rainbow Trout Growth during Hatchery Rearing in Circular Tanks. International Journal of Aquaculture and Fishery Sciences, 4, 27-30.

[31] Crank, K.M., Kientz, J.L. and Barnes, M.E. (2019). An Evaluation of Vertically-suspended Environmental Enrichment Structures during Rainbow Trout Oncorhynchus mykiss Rearing. North American Journal of Aquaculture, 81, 94-100. https://doi.org/10.1002/naaq.10064

[32] Huysman, N., Krebs, E., Voorhees, J.M. and Barnes M.E. (2019). Use of Two Vertically-Suspended Environmental Enrichment Arrays during Rainbow Trout Rearing in Circular Tanks. International Journal of Innovative Studies in Aquatic Biology and Fisheries, 5, 25-30. https://doi.org/10.20431/2454-7670.0501005

[33] Jones, M.D., Krebs, E., Huysman, N., Voorhees, J.M. and Barnes, M.E. (2019). 
Rearing Performance of Atlantic Salmon Grown in Circular Tanks with Vertically-Suspended Environmental Enrichment. Open Journal of Animal Science, 9, 249-257. https://doi.org/10.4236/ojas.2019.92021

[34] Rosburg, A.J., Fletcher, B.L., Barnes, M.E., Treft, C.E. and Bursell, B.R. (2019). Vertically suspended Environmental Enrichment Structures Improve the Growth of Juvenile Landlocked Fall Chinook Salmon. International Journal of Innovative Studies in Aquatic Biology and Fisheries, 5, 17-24.

https://doi.org/10.20431/2454-7670.0501004

[35] White, S.C., Krebs, E., Huysman, N., Voorhees, J.M. and Barnes, M.E. (2019) Use of Suspended Plastic Conduit Arrays during Brown Trout and Rainbow Trout Rearing in Circular Tanks. North American Journal of Aquaculture, 81, 101-106. https://doi.org/10.1002/naaq.10076

[36] Oca, J. and Masalo, I. (2016) Influence of Fish Swimming on the Flow Pattern of Circular Tanks. Aquacultural Engineering, 74, 84-95.

https://doi.org/10.1016/j.aquaeng.2016.07.001

[37] Sumida, T., Kawahara, H., Shiotani, S., Sakakura, Y. and Hagiwara, A. (2013) Estimation of Flow Fields in a Model of a Rearing Tank for Marine Fish Larvae by Numerical Calculation. Proceedings of the 23rd International Offshore and Polar Engineering Conference, Anchorage, 30 June-5 July 2013, 6 p.

[38] Fausch, K.D. (1984) Profitable Stream Positions for Salmonids: Relating Specific Growth Rate to Net Energy Gain. Canadian Journal of Zoology, 62, 441-445. https://doi.org/10.1139/z84-067

[39] Ibarz, A., Felip, O., Fernández-Borràs, J., Martín-Pérez, M., Blasco J. and Torrella, J.R. (2011) Sustained Swimming Improves Muscle Growth and Cellularity in Gilthead Sea Bream. Journal of Comparative Physiology B, 181, 209-217. https://doi.org/10.1007/s00360-010-0516-4

[40] Good, C., May, T., Crouse, C., Summerfelt, S. and Welch, T.J. (2016) Assessing the Impacts of Swimming Exercise and the Relative Susceptibility of Rainbow Trout Oncorhynchus mykiss (Walbaum) and Atlantic Salmon Salmo salar L. Following Injection Challenge with Weissella ceti. Journal of Fish Diseases, 39, 1387-1391.

[41] Liu, G.Y., Wu, Y.J., Qin, X.H., Shi, X.T. and Wang, X.L. (2018) The Effect of Aerobic Exercise Training on Growth Performance, Innate Immune Response, and Disease Resistance in Juvenile Schizothorax prenanti. Aquaculture, 486, 18-25. https://doi.org/10.1016/j.aquaculture.2017.12.006

[42] Waldrop, T., Summerfelt, S., Mazik, P. and Good, C. (2018) The Effects of Swimming Exercise and Dissolved Oxygen on Growth Performance, Fin Condition and Precocious Maturation of Early-Rearing Atlantic Salmon Salmo salar. Aquaculture Research, 49, 801-808. https://doi.org/10.1111/are.13511

[43] Beuntello, J.A., Gatlin, D.M. and Neill, W.H. (2000) Effects of Water Temperature and Dissolved Oxygen on Daily Feed Consumption, Feed Utilization and Growth of Channel Catfish (Ictalurus punctatus). Aquaculture, 182, 339-352.

https://doi.org/10.1016/S0044-8486(99)00274-4 